PAPER

\title{
Outcome in patients with basilar artery occlusion treated conventionally
}

\author{
W J Schonewille, A Algra, J Serena, C A Molina, L J Kappelle
}

J Neurol Neurosurg Psychiatry 2005;76:1238-1241. doi: 10.1136/jnnp.2004.049924

See end of article for authors' affiliations

.....................

Correspondence to: Dr Wouter J Schonewille, University Medical Centre Utrecht, Department of Neurology, HP G 03.228, PO box 85500, 3508 GA Utrecht, Netherlands; w.j.schonewille@neuro. azu.nl

Received 16 July 2004

In revised form

3 January 2005

Accepted 9 January 2005

\begin{abstract}
Background: Most data on the outcome of basilar artery occlusion are from recent case series of patients treated with intra-arterial thrombolysis. The limited knowledge on the outcome after a conventional treatment approach comes from a few small case series of highly selected patients.

Objective: To provide more data on the outcome of conventional treatment.

Methods: Data were analysed on patients from three centres with symptomatic basilar artery occlusion treated conventionally. Conventional therapy was defined as treatment with antiplatelets, anticoagulation, or both.

Results: Data were available on 82 patients. The case fatality was $40 \%$. Among survivors, $65 \%$ remained dependent (Rankin score 4-5). Patients younger than 60 years (odds ratio $=3.1$ ( $95 \%$ confidence interval, 1.0 to 9.5)) and those with a minor stroke (OR =3.1 (1.0 to 9.6)) were more likely to have a good outcome (Rankin score $0-3)$. Patients with a progressive stroke were less likely to have a good outcome $(O R=0.3$ (0.08 to 1.2)) than patients with a maximum deficit at onset or fluctuating symptoms at presentation.

Conclusions: Conventional treatment of symptomatic basilar artery occlusion is associated with a poor outcome in almost $80 \%$ of patients, which emphasises the importance of the search for a more effective treatment approach.
\end{abstract}

$\mathrm{U}$ nlike the anterior circulation, the posterior circulation depends on one main artery. The basilar artery supplies the occipital lobes, part of the temporal lobes, the thalami, the cerebellum, and most importantly the brain stem. Acute occlusion of the basilar artery has been associated with a high case fatality rate and morbidity, although reliable data about the natural history are lacking. Studies on the outcome of basilar artery occlusion using a conventional treatment approach have been small and have described the outcome of highly selected patients or used very broad definitions, including vertebral and branch artery occlusions. ${ }^{1-10}$ Hacke et al, in the largest study to date with detailed individual angiographic data $(n=22)$, found a case fatality of $86 \%$ in patients treated conventionally. ${ }^{11}{ }^{12}$ Recently several uncontrolled larger case series of patients treated with intra-arterial thrombolysis have found case fatality rates ranging between $20 \%$ and $70 \% .{ }^{11-25}$ More data are needed on the outcome of conventional treatment to validate these results.

\section{METHODS}

Three centres participated in our database search: the University Medical Centre Utrecht, Netherlands; Hospital Universitari Doctor Josep Trueta in Girona, Spain; and Hospital Vall d'Hebron in Barcelona, Spain. All are academic hospitals with a special interest in stroke. The databases used in the three centres were constructed in similar fashion, with comparable definitions and outcome measures. Patients' records were reviewed for details of clinical presentation. Patients were included in the study if they fulfilled at least one of the following diagnostic criteria:

- (A) acute neurological deficit attributable to the posterior circulation and basilar artery occlusion on angiography, magnetic resonance angiography (MRA), computed tomography angiography (CTA), or necropsy;
- (B) acute "classic" symptoms of basilar artery occlusion including alternating hemiplegia/tetraplegia with brain stem deficits, leading to a locked-in state, coma, or death;

- (C) coma or loss of consciousness and acute posterior circulation infarction on computed tomography (CT) or magnetic resonance imaging (MRI).

Patients were considered to have been treated conventionally if they had not received any specified treatment, or if they had been treated with antiplatelets, anticoagulation, or a combination of the two. During the time period studied, thrombolytic treatment was not a standard option in these three centres. Most studies of intravenous or intra-arterial thrombolysis in acute stroke have used a modified Rankin score of 0-1 or 0-2 to define good outcome. Because of the poor natural history of basilar artery occlusion we used a modified Rankin score of 0-3 as a measure of independence and good outcome. Outcome was assessed at the time of discharge or in-hospital death, without knowledge of baseline characteristics pertinent to the outcome. Stroke severity at the time of presentation was considered minor if a patient was non-comatose and was not tetraplegic, intubated, or locked-in.

We distinguished three different types of clinical presentation: fluctuating symptoms with alternating periods of neurological worsening (at least one) and improvement, without full recovery; progressive stroke with a progressive worsening of deficit, stepwise or gradual, but without intermittent periods of improvement; and maximum deficit from onset with or without subsequent improvement or fluctuating symptoms.

\section{Data analysis}

We assessed the relation between potential prognostic factors and outcome by univariate logistic regression. The strength of a relation was expressed as an odds ratio (OR) with corresponding 95\% confidence interval (CI) to describe its precision. 
Table 1 Patient characteristics and outcome: three centre database search $(n=82)$

\begin{tabular}{|c|c|c|c|c|c|}
\hline \multirow[b]{2}{*}{ Patient characteristics } & \multirow[b]{2}{*}{$n$} & \multirow[b]{2}{*}{$\%$} & \multicolumn{2}{|c|}{ Rankin score } & \multirow[b]{2}{*}{ Death (n (\%) } \\
\hline & & & $0-3$ (n $(\%))$ & 4-5 (n (\%)) & \\
\hline All & 82 & & $17(21)$ & $32(39)$ & $33(40)$ \\
\hline Age $<60$ years & 35 & 43 & 11 (31) & $18(51)$ & $6(17)$ \\
\hline Male sex & 44 & 54 & $12(27)$ & $15(34)$ & $17(39)$ \\
\hline Fluctuating symptoms & 13 & 16 & $3(23)$ & $7(54)$ & $3(23)$ \\
\hline Progressive stroke & 29 & 35 & $3(10)$ & $10(35)$ & $16(55)$ \\
\hline Maximum from onset & 40 & 49 & $11(28)$ & $15(38)$ & $14(35)$ \\
\hline Coma & 28 & 34 & $6(21)$ & $7(25)$ & $15(54)$ \\
\hline Locked-in/tetraplegia & 18 & 22 & 0 & $10(56)$ & $8(44)$ \\
\hline Intubated & 18 & 22 & $3(17)$ & $4(22)$ & $11(61)$ \\
\hline Minor stroke & 35 & 43 & $11(31)$ & $15(43)$ & $9(26)$ \\
\hline Previous TIAs* & 16 & 20 & $4(25)$ & $9(56)$ & $3(19)$ \\
\hline Previous stroke ${ }^{*}$ & 16 & 20 & $1(6)$ & $8(50)$ & 7 (44) \\
\hline Use of antiplatelet agents & 55 & 67 & $10(18)$ & $22(40)$ & $23(42)$ \\
\hline Use of anticoagulation & 27 & 33 & $7(26)$ & $10(37)$ & $10(37)$ \\
\hline Diagnostic category A & 25 & 30 & $9(36)$ & $6(24)$ & $10(40)$ \\
\hline Diagnostic category $\mathrm{Bf}$ & 26 & 32 & 0 & $13(50)$ & $13(50)$ \\
\hline Diagnostic category $C \S$ & 31 & 38 & $8(26)$ & $13(42)$ & $10(32)$ \\
\hline
\end{tabular}

\section{RESULTS}

On our database search we found 82 patients with the clinical diagnosis of symptomatic basilar artery occlusion, treated conventionally, over a period of 20 database years ( 11 years for Utrecht, 5 years for Girona, and 4 years for Barcelona), ending in 2002 (table 1). Eleven patients with basilar artery occlusion treated with intravenous $(\mathrm{n}=2$, from two centres) or intra-arterial thrombolysis $(n=9$, three in each centre) where excluded from the study. These were all treated within the first three hours in cases of intravenous treatment or within 12 hours in cases of intra-arterial thrombolysis. Fifty three patients were treated in Utrecht, 20 in Girona, and nine in Barcelona. Of these 82 patients, 25 were categorised in diagnostic group A, 26 in group B, and 31 in group C. All patients in group B had a poor outcome (Rankin score 4-6), $74 \%$ had a poor outcome in group C, and $64 \%$ in group A. The small number of patients who had necropsy $(n=2)$ did not cause a bias towards a worse outcome in group A.

The poor outcome in patients with basilar artery occlusion did not improve in more recent years (82\% in 1997 to $2002 \mathrm{v}$ $74 \%$ in 1991 to 1996), despite more patients being diagnosed with a minor stroke $(47 \% \quad v 35 \%)$. The mean time to assessment was 28 days (range 1 to 280 ) for all patients. Twenty nine per cent of the deaths occurred within the first 48 hours and $53 \%$ within the first week, with a mean time to death of 12 days (range 1 to 76). Discharge of the 42 survivors was after a mean of 40 days (range 3 to 280 ); $61 \%$ were discharged within a month, $84 \%$ within two months, and $91 \%$ within three months. There was a clear trend towards a better outcome in patients younger than 60 years (odds ratio $(\mathrm{OR})=3.1$ (95\% confidence interval, 1.0 to 9.5$)$ ) and patients with a minor stroke $(\mathrm{OR}=3.1$ ( 1.0 to 9.6)). Patients who presented with a progressive stroke were less likely to have a good outcome than patients presenting with fluctuating symptoms or a maximum deficit from onset $(\mathrm{OR}=0.3(0.08$ to 1.2$)$ (table 2$)$.

\section{DISCUSSION}

Basilar artery occlusion has generally been associated with a high mortality and morbidity. Among the patients from our database search - the largest series to date on patients treated conventionally_almost $80 \%$ had a poor outcome, with a case fatality of $40 \%$ and the presence of a severe residual deficit in more than $65 \%$ of survivors.

The results of our study should be interpreted with caution. Outcome in our study was assessed after a mean of 28 days. This information, however, is lacking in the previous case series, possible explaining the different findings among studies, because outcome tends to be better after a longer follow up. The three diagnostic groups recognised in the database search by no means represent the whole range of patients with basilar artery occlusion. However, we believe that with a combination of strict clinical and simple frequently used imaging techniques as inclusion criteria for our database search, our patient group is more representative of the conventional treatment approach than most previously published series in which individual patient data were described (table 3 ). These series included cases confirmed

Table 2 Predictors of good outcome: three centre database search $(n=82)$

\begin{tabular}{llll}
\hline & \multicolumn{2}{l}{ Good outcome } & \\
\cline { 2 - 3 } Characteristic & Present & Absent & OR (95\% Cl) \\
\hline Age $\leqslant 60$ years & $31 \%(11 / 35)$ & $13 \%(6 / 47)$ & $3.1(1.0$ to 9.5$)$ \\
Male sex & $27 \%(12 / 44)$ & $13 \%(5 / 38)$ & $2.5(0.8$ to 7.8$)$ \\
Fluctuating stroke & $23 \%(3 / 13)$ & $20 \%(14 / 69)$ & $1.2(0.3$ to 4.9$)$ \\
Progressive stroke & $10 \%(3 / 29)$ & $26 \%(14 / 53)$ & $0.3(0.08$ to 1.2$)$ \\
Maximum from onset & $28 \%(11 / 40)$ & $14 \%(6 / 42)$ & $2.3(0.8$ to 6.9$)$ \\
Coma & $21 \%(6 / 28)$ & $20 \%(11 / 54)$ & $1.1(0.3$ to 3.3$)$ \\
Minor stroke & $31 \%(11 / 35)$ & $13 \%(6 / 47)$ & $3.1(1.0$ to 9.6$)$ \\
Previous TIAs* & $25 \%(4 / 16)$ & $20 \%(13 / 66)$ & $1.4(0.4$ to 4.9$)$ \\
Previous stroke* & $6 \%(1 / 16)$ & $24 \%(16 / 66)$ & $0.2(0.03$ to 1.7$)$ \\
\hline *Posterior circulation. & & & \\
Cl, confidence interval; OR, odds ratio; TIA, transient ischaemic attack. & \\
\hline
\end{tabular}


by MRA or conventional angiography. It is unlikely that, in a disorder for which no specific treatment other than antithrombotic agents was available, all consecutive patients with the possible clinical diagnosis of basilar artery occlusion had radiological confirmation of their occlusion, while a few would have been imaged within the first 24 hours, causing an important selection bias. This is especially true for the older case series done at a time when non-invasive vascular imaging was not an option. ${ }^{811}$ In our database review, basilar artery occlusion was only confirmed by radiological imaging in $30 \%$ of patients (group A). Interestingly these patients had the best outcome, despite having similar stroke severity at onset. One possible explanation for the better outcome in patients who had radiological confirmation of their occlusion is that most were imaged more than 24 hours after the time of occlusion and had already survived the most critical phase. Our patient groups B and C, presenting with a severe progressive deficit or an acute loss of consciousness, are probably most representative of the way most physicians would think of a typical patient with basilar artery occlusion. However, this latter group excludes an important subgroup of patients with a minor stroke, causing a bias towards the inclusion of patients with a more severe deficit.

The more frequent use of non-invasive vascular imaging in the two most recent studies could have caused an increase in the number of patients diagnosed with basilar artery occlusion with a minor deficit. ${ }^{9}{ }^{10}$ Voetsch et a ${ }^{10}$ described the outcome of 87 patients with occlusive basilar artery disease including patients with basilar artery stenosis and 32 patients with basilar artery occlusion documented by transcranial Doppler, MRA, or conventional angiography. They found an overall case fatality of only $2.3 \%$. No individual patient data were described concerning stroke severity, treatment, or time to radiological confirmation. Most patients had a minor stroke, and only five had tetraparesis or tetraplegia; one patient was locked-in and 16 had a decreased level of consciousness. The only data available on the subgroup of patients with basilar artery occlusion described a poor outcome (death or major disability) in $40 \%$ of patients with an atherosclerotic occlusion.

The severity of deficit in the 20 patients described by Archer and Horenstein ${ }^{8}$ seems comparable to our patient group. In contrast to our results, they found coma to be an important predictor of poor outcome. This difference might reflect improved monitoring and treatment options in comatose patients, as on average our patients were treated 25 years later. The mayor difference in outcome with the study of Hacke et al is more difficult to explain, as all their patients had minimal symptoms $(\mathrm{n}=2)$ or a stable moderate brain stem stroke $(\mathrm{n}=20) .{ }^{11}{ }^{12}$

The numbers of patients described by Moscow and Newton $^{7}$ and Devuyst et al ${ }^{9}$ are too small for a meaningful comparison, but interestingly both studies describe the same

Table 3 Case series on the outcome of basilar artery occlusion treated conventionally

\begin{tabular}{llllll}
\hline & & \multicolumn{4}{c}{ Rankin score } \\
\cline { 5 - 6 } Study & Year & $\mathbf{n}$ & $\mathbf{0 - 3}$ & $\mathbf{4 - 5}$ & $\mathbf{6}$ \\
\hline Moscow $^{7}$ & 1973 & 9 & 44 & 22 & 33 \\
Archer $^{8}$ & 1977 & 20 & 5 & 25 & 70 \\
Hacke $^{11}$ & 1988 & 22 & 14 & & 86 \\
Devuyst $^{9}$ & 2002 & 9 & 66 & 22 & 11 \\
Present study & 2004 & 82 & 21 & 39 & 40 \\
Total & & 142 & 21 & 28 & 49 \\
\end{tabular}

possible positive influence on outcome of previous TIAs as found in our study.

The emphasis in our study was on the outcome in relation with the clinical presentation; because of the low rate of vascular imaging the aetiology could not reliably be assessed. We identified three potentially important predictors of good outcome in patients treated conventionally: young age, limited stroke severity, and a presentation with fluctuating symptoms or a maximum deficit from onset (table 2). Age could influence both the spontaneous recanalisation rate and the quality of collateral flow, as the rate of atherothrombotic disease increases with age. Initial stroke severity could be an indicator of the quality of collateral flow at the time of occlusion, and progression of deficit could represent failure of augmentation of collateral flow or growth of the thrombus.

In conclusion, the outcome of patients with basilar artery occlusion treated conventionally varies considerably among case series. Considering our limited knowledge on the outcome of patients treated conventionally, future studies on the outcome of basilar artery occlusion should not be limited to patients receiving more aggressive treatment.

\section{Authors' affiliations}

W J Schonewille, A Algra, L J Kappelle, Department of Neurology, Rudolph Magnus Institute of Neuroscience, University Medical Centre Utrecht, Utrecht, Netherlands

J Serena, Department of Neurology, Hospital Universitari Doctor Josep Trueta, Girona, Spain

C A Molina, Cerebrovascular Unit, Department of Neurology, Hospital Vall d'Hebron, Barcelona, Spain

Competing interests: none declared

\section{REFERENCES}

1 Kubik CS, Adams RD. Occlusion of the basilar artery - a clinical and pathologic study. Brain 1946;69:73-121.

2 Biemond A. Thrombosis of the basilar artery and the vascularization of the brainstem. Brain 1951;74:300-17

3 Fields WS, Ratinov G, Weibel J, et al. Survival following basilar artery occlusion. Arch Neurol 1966;15:463-71.

4 Castaigne P, Lhermitte F, Gautier JC, et al. Arterial occlusions in the vertebrobasilar system. A study of 44 patients with post-mortem data. Brain 1973;96:133-54.

5 Caplan LR. Occlusion of the vertebral or basilar artery. Follow-up analysis of some patients with a benign outcome. Stroke 1979;10:277-82.

6 Brandt T, Pessin MS, Kwan ES, et al. Survival with basilar artery occlusion. Cerebrovasc Dis 1995;5:182-7.

7 Moscow NP, Newton TH. Angiographic implications in diagnosis and prognosis of basilar artery occlusion. Am J Radiol 1973;1 19:597-603

8 Archer CR, Horenstein S. Basilar artery occlusion. Clinical and radiological correlation. Stroke 1977;8:383-90.

9 Devuyst G, Bogousslavsky J, Meuli R, et al. Stroke or transient ischemic attacks with basilar artery stenosis or occlusion. Clinical patterns and outcome. Arch Neurol 2002;59:567-73.

10 Voetsch B, DeWitt LD, Pessin MS, et al. Basilar artery occlusive disease in the New England Medical Center Posterior Circulation Registry. Arch Neurol 2004;61:496-504.

11 Hacke W, Zeumer $\mathrm{H}$, Ferbert A, et al. Intra-arterial thrombolytic therapy improves outcome in patients with acute vertebrobasilar occlusive disease. Stroke 1988;19:1216-22.

12 Bruckmann H, Ferbert A, del Zoppo GJ, et al. Acute vertebral-basilar thrombosis: Angiologic-clinical comparison and therapeutic implications. Acta Radiol 1987;369(suppl):38-42.

13 Zeumer H, Hacke W, Ringelstein EB. Local intraarterial thrombolysis in vertebrobasilar thromboembolic disease. Am J Neuroradiol 1983;4:401-4.

14 Zeumer H, Freitag HJ, Gryska U, et al. Local intraarterial fibrinolysis in acute vertebrobasilar occlusion. Technical development and recent results. Neuroradiology 1989;31:336-40.

15 Bockenheimer S, Reinhuber F, Mohs C. [Intraarterielle thrombolyse hirnversorgender gefasse]. Radiologe 1991;31:210-15.

16 Sasaki O, Takeuchi S, Koike T, et al. Fibrinolytic therapy for acute embolic stroke: intravenous, intracarotid, and intra-arterial local approaches. Neurosurgery 1995;36:246-53.

17 Brandt T, von Kummer R, Muller-Kuppers M, et al. Thrombolytic therapy of acute basilar artery occlusion. Variables affecting recanalization and outcome. Stroke 1996;27:875-81.

18 Wijdicks EF, Nichols DA, Thielen KR, et al. Intra-arterial thrombolysis in acute basilar artery thromboembolism: the initial Mayo Clinic experience. Mayo Clin Proc 1997; 72:1005-13. 
19 Cross DT, Moran CJ, Atkins PT, et al. Relationship between clot location and outcome after basilar artery thrombolysis. Am J Neuradiol 1997; 18:1221-8

20 Mitchell PJ, Gerraty RP, Donnan GA, et al. For the AUST study group. Thrombolysis in the vertebrobasilar circulation: the Australian Urokinase Stroke Trial, A pilot study. Cerebrovasc Dis 1997;7:94-9

21 Gonner F, Remonda L, Mattle H, et al. Local intra-arterial thrombolysis in acute ischemic stroke. Stroke 1998;29:1894-900.

22 Levy El, Firlik $A D$, Wisniewski $S$, et al. Factors affecting survival rates for acute vertebrobasilar artery occlusions treated with intra-arterial thrombolytic therapy: A meta-analytical approach. Neurosurgery 1999;45:539-48

23 Berg-Dammer E, Felber SR, Henkes $\mathrm{H}$, et al. Long-term outcome after local intra-arterial fibrinolysis of basilar artery thrombosis. Cerebrovasc Dis 2000;10:183-8.

24 Sliwka U, Mull M, Stelzer A, et al. Long-term follow-up of patients after intraarterial thrombolytic therapy of acute vertebrobasilar artery occlusion. Cerebrovasc Dis 2001;12:214-19.

25 Eckert B, Kucinski T, Pfeiffer G, et al. Endovascular therapy of acute vertebrobasilar occlusion: early treatment onset as the most important factor. Cerebrovasc Dis 2002; 14:42-50.

\section{HISTORICAL NOTE}

\section{Marshall Hall and "Romberg's sign"}

$M$ arshall Hall is famous, inter alia, for his concept of the spinal reflex $\operatorname{arc}^{1}$ when he demonstrated reflex function-an "excito-motory system"2 —of the spinal cord and nerves in animals after removal of the brain. This ended the misconceptions that the soul and psychic functions resided in the cord as well as in the brain. Often overlooked, in his Lectures on the nervous system and its diseases $(1836)^{3}$, he predated Romberg's account of sensory ataxia, in tabes dorsalis. Hall plainly described the loss of postural control in the dark of a patient with proprioceptive loss:

"I have this day seen a patient with a slight degree of paralysis of feeling and of voluntary motion of the lower limbs. He walks safely while his eyes are fixed upon the ground, but stumbles immediately if he attempts to walk in the dark. His own words are 'my feet are numb; I cannot tell in the dark where they are, and I cannot poise myself.' The voluntary motions are regulated by the sense of touch, when this is unimpaired; or by that of sight, when the touch is paralyzed."

Hall failed to consider fully its anatomical substrate and its implications for cord physiology. Surprisingly, he did not advocate the sign in clinical practice, but the importance of his description is undeniable.

Romberg published his Lehrbuch der Nervenkrankheiten in sections between 1840 and 1846. The depiction ${ }^{4}$ of that most misspelled of all eponyms ${ }^{5}$ lies in his account of sensory ataxia in tabes dorsalis ${ }^{6}$ (Romberg's sign, named "locomotor ataxia" by Duchenne in 1858/9). Romberg reported:

"... The feet feel numbed in standing, walking or lying down, and the patient has the sensation as if they were covered in fur; the resistance of the ground is not felt... The gait begins to be insecure... he puts down his feet with greater force... The individual keeps his eyes on his feet to prevent his movements from becoming still more unsteady. If he is ordered to close his eyes while in the erect posture, he at once commences to totter and swing from side to side; the insecurity of his gait also exhibits itself more in the dark."
He gave a full description of the tabetic gait, urinary frequency, retention, incontinence, and the classical lightning and girdle pains.

But Marshall Hall was not alone in anticipating Romberg's sign for in 1840 Bernardus Brach ${ }^{7}$ had given an earlier account. And Romberg's teacher, Ernst Horn (1774-1848), had shown dorsal cord atrophy in a tabetic at autopsy. ${ }^{8}$ Moreover, five of Horn's students wrote their doctoral theses on the same subject, published between 1817 and 1827 .

Robert Bentley Todd, however, like Romberg, gave an exemplary detailed account of tabes in $1847^{\circ}$, of which Gowers said:

"The credit of the discovery of the disease belongs, if to anyone, unquestionably to Todd."

\section{J M S Pearce 304 Beverley Road, Anlaby, Hull, East Yorkshire HU10 7BG, UK; jmspearce@freenet.co.uk \\ Competing interests: none declared}

\section{References}

1 Pearce JMS. Marshall Hall and the concepts of reflex action. J Neurol Neurosurg Psychiatry 1997;62:228.

2 Hall M. Memoirs on the nervous system. Memoir II. On the true spinal marrow and the excito-motory system. London Sherwood, Gilbert and Piper, 1837. [Read to the Royal Society, but rejected for publication].

3 Hall Marshall. Lectures on the nervous system and its diseases. London: Sherwood, Gilbert and Piper, 1836:27.

4 Lanska DJ, Goetz CG. Romberg's sign Development, adoption, and adaptation in the 19th century. Neurology 2000;55:1201-6.

5 Pearce JMS. Romberg's Sign. J Neurology Neurosurgery Psychiatry 1993;56:51.

6 Romberg MH. Lehrbuch der Nervenkrankheiten des Menschen. Bd.1. Berlin, A. Duncker, 1846. pp795. [A Manual of the Nervous Diseases of Man, EH Sieveking trans. London: Sydenham society, 1853;2:395-401.

7 Brach B. Einige Worte über einen nicht hinlänglich beachteten Punkt aus der Physiologie der Nerven und eine eigenthümliche Art von Lähmung. Medicinische Zeitung 1840;9:215-17, cited by Lanska DJ, Goetz CG. Romberg's sign Development, adoption, and adaptation in the 19th century. Neurology 2000;55:1201-6.

8 Schiller F. Venery. The spinal cord, and tabes dorsalis before Romberg: the contribution of Ernst Horn, J Nerv Ment Dis 1976;163:1-9.

9 Todd RB. Cyclopaedia of Anatomy and physiology, vol 3. p. 721. London: Longman \& Roberts, Longman, Brown, Green, 1847. 